\title{
Vaccination against hepatitis b virus: are Italian medical students sufficiently protected after the public vaccination programme?
}

Monica Lamberti ${ }^{{ }^{* \dagger}}$, Alfredo De Rosa ${ }^{2^{* \dagger}}$, Elpidio Maria Garzillo ${ }^{1}$, Anna Rita Corvino ${ }^{1}$, Nicola Sannolo ${ }^{1}$, Stefania De Pascalis ${ }^{3}$, Eliana Di Fiore ${ }^{1}$, Claudia Westermann ${ }^{4}$, Antonio Arnese ${ }^{1}$, Di Giuseppe Gabriella ${ }^{1}$, Albert Nienhaus ${ }^{4,5}$, Antônio Paulino Ribeiro Sobrinho ${ }^{6}$ and Nicola Coppola ${ }^{3}$

\begin{abstract}
Background: The development of a vaccine against hepatitis B virus (HBV) has been a major achievement in terms of prevention of HBV infection. For the present study, we analysed the long-term immunogenicity and effectiveness of HBV vaccination among healthcare students with different working seniorities.

Methods: A cross-sectional study of undergraduate and postgraduate students attending the Medical School of the Second University of Naples was conducted between September 2012 and December 2014. HBV serum markers were determined and multivariate logistic regression analysis was used to identify factors associated with the level of long-term immunogenicity.
\end{abstract}

Results: Of the 2,932 subjects evaluated, only $33(1.1 \%)$ declared no history of vaccination. All vaccinated subjects were $\mathrm{HBsAg} / \mathrm{anti}-\mathrm{HBC}$ negative, 459 of which had an anti-HBs titre $<10 \mathrm{IU} / \mathrm{L}$. The latter were younger, more likely to be attending a healthcare profession school (i.e., dental hygienists, nursing, paediatric nursing, radiography and midwifery) than a medical school (at either undergraduate or postgraduate level) and more likely to have been vaccinated in infancy.

Conclusion: The results of this study suggest that assessment of HBV serum markers in workers potentially exposed to hospital infections is useful to identify small numbers of unvaccinated subjects or vaccinated subjects with low antibody titre, all of whom should be referred to a booster series of vaccinations.

Keywords: HBV infection, HBV vaccination, Anti-HBs titre, Healthcare students

\section{Background}

Hepatitis B virus (HBV) can cause dreadful infectious diseases and, as such, is a major global health problem [1]. Infection can be asymptomatic or symptomatic, can take the form of acute or chronic liver disease and is potentially fatal. The World Health Organisation

\footnotetext{
*Correspondence: monicalamberti@libero.it; alfredo.derosa@unina2.it ${ }^{\dagger}$ Equal contributors

'Department of Experimental Medicine, Section of Hygiene, Occupational Medicine and Forensic Medicine, Second University of Naples, Via dei Crecchi 16, Naples 80133, Italy

${ }^{2}$ Department of Orthodontics, Second University of Naples, Naples, Italy

Full list of author information is available at the end of the article
}

(WHO) estimates that, globally, about 2 billion people have been infected with HBV, more than 350 million are chronically infected, and nearly one million per year die from its acute or chronic sequelae [2]. The risk run by healthcare personnel $(\mathrm{HCP})$ of contracting $\mathrm{HBV}$ is four times greater than that of the general adult population [3]. The most common routes of transmission from patients to HCP are needlestick and other sharps injuries, followed by mucocutaneous exposure [4]. The risk of transmission of the virus per needlestick injury from a patient infected with HBV is $37-62 \%$, among the highest risk rates for a virus [5].

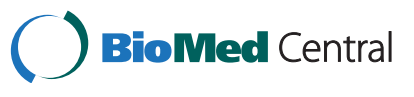

(c) 2015 Lamberti et al. Open Access This article is distributed under the terms of the Creative Commons Attribution 4.0 International License (http://creativecommons.org/licenses/by/4.0/), which permits unrestricted use, distribution, and reproduction in any medium, provided you give appropriate credit to the original author(s) and the source, provide a link to the Creative Commons license, and indicate if changes were made. The Creative Commons Public Domain Dedication waiver (http://creativecommons.org/publicdomain/zero/1.0/) applies to the data made available in this article, unless otherwise stated. 
In addition to HCP, students and assistants in training are also potentially exposed to hospital infections [6]. A range of different measures and interventions, such as the use of safety devices, has helped to reduce the risk of HBV transmission to HCP, but the development of HBV vaccines must be considered the major achievement in terms of prevention of HBV infection [4].

Since 1991, there has been a compulsory vaccination programme in Italy for infants: the procedure is reported on a vaccination card, a document designed exclusively to record basic identifying information and the immunization services received. The vaccination coverage has been high (94\%), and the programme has greatly reduced the incidence of HBV infection [7]. All babies are vaccinated (at month 3, 5 and 11) to prevent the risk of acquiring $\mathrm{HBV}$ infection by perinatal and familial transmission; moreover, during the first 12 years of application of the programme, all children aged 12 were also vaccinated to prevent HBV transmission by unsafe sexual activity or intravenous drug use. This strategy permitted the programme to cover the Italian population aged $0-24$ years by 2003 [8].

It is generally observed that antibody titres decline over time following immunization, resulting in an increased rate of infection, especially when the titre of the antibody to hepatitis B surface antigen ( $\mathrm{HBsAg}$ ) falls below the protective cut-off level of $\geq 10 \mathrm{mIU} / \mathrm{mL}$ [9]. The present study was therefore carried out to evaluate the long-term immunogenicity and effectiveness of the Italian HBV vaccination programme in students attending the medical and healthcare schools of the Second University of Naples, Italy, and to identify independent predictive factors of long-term immunogenicity.

\section{Methods}

This study was conducted at the Second University of Naples, Naples, Italy, from September 2012 to December 2014. Based on the risk assessment document, during this period we carried out a health surveillance programme of third and sixth year medical school students, first and third year health profession school students (three-year nursing, dental hygienists, paediatric nursing, radiography and midwifery courses), and first and third year students of the university's specialisation schools (all of whom were post-medical school students). All were actively recruited before any possible exposure to risky procedures or patients connected with the educational path, as established by our health protocol $[10,11]$. HBV serum markers (HBsAg, antiHBs and total anti-HBc) were determined at year 3 for the medical school students, and year 1 for students of the health profession schools and of the specialisation schools. HBsAg titre was re-evaluated again at a later time only in subjects with a low $(<10 \mathrm{IU} / \mathrm{L})$ anti-HBs titre.

After obtaining informed written consent, all students visited for the first time were asked to complete a pre- coded questionnaire stating their age, gender, hepatitis $B$ vaccination status, previous exposure to $\mathrm{HBV}$ and educational level. The information on $\mathrm{HBV}$ vaccination given by the students was always checked against their vaccination cards. A blood sample was taken from each participant under strict aseptic conditions in a plain vaccutainer. Blood was allowed to clot and serum was separated and stored at $-20{ }^{\circ} \mathrm{C}$ until testing. $\mathrm{HBV}$ serum markers (HBsAg, anti-HBs and total anti-HBc) were determined using commercial immunoenzymatic assays (Abbott Laboratories, North Chicago, IL, USA). Anti-HBs titres were extrapolated from a calibration curve generated using the WHO reference standard and are expressed in IU/L. In particular, actual values were obtained for anti-HBs titres between 10 and $400 \mathrm{IU} /$ $\mathrm{mL}$, and for this interval the geometric mean was calculated using standard procedures; for values $<10 \mathrm{IU} / \mathrm{mL}$ or $>400$ $\mathrm{IU} / \mathrm{mL}$, the laboratory readout indicated only either "under $10 \mathrm{IU} / \mathrm{mL}$ " or "over $400 \mathrm{IU} / \mathrm{mL}$ ", respectively.

According to Italian legal guidelines for observational studies, ethical approval for conducting this survey was unnecessary and, accordingly, cross-sectional studies did not require formal approval by local institutional review boards [12]. Personal information on the subjects included in the study was protected according to Italian law [13]. Statistical analysis was performed with StatGraph v3.0. Continuous variables are given as mean \pm standard deviation, and categorical variables as the absolute value and relative frequency. Differences in mean were evaluated using an unpaired Student t-test, and the chi-squared test was applied to categorical variables. A $p$-value of $<0.05$ was considered to be statistically significant.

\section{Results}

In total, 2,932 students attending the medical school, the healthcare profession schools and the specialisation schools of the Second University of Naples were screened from September 1, 2012, to December 31, 2014. On the questionnaire, 2,899 (98.9 \%) students declared a history of HBV vaccination. The remaining 33 (1.1\%) were not born in Italy: 32 were HBsAg/anti-HBs/ anti-HBc negative, and one was $\mathrm{HBsAg}$ positive; 23 were attending a healthcare profession school, seven the medical school and three were specialising doctors. All were being evaluated for HBV for the first time.

The HBsAg positive subject was attending the first year of the thoracic surgery specialisation school, and on the advice of the infectious disease specialist, was started on a course of antiviral therapy and included in a follow-up programme for the monitoring of viral load. The student returned to work under the obligation of using personal protective equipment (Kevlar cut-resistant gloves), had to present at the customary medical check-ups with a 
Table 1 Demographics of vaccinated, HBsAg-negative students

\begin{tabular}{|c|c|c|}
\hline \multicolumn{2}{|l|}{ Characteristic } & Value \\
\hline \multicolumn{2}{|l|}{ No. of subjects } & 2,899 \\
\hline \multicolumn{2}{|l|}{ Age in years } & $26 \pm 4.8$ \\
\hline \multicolumn{2}{|c|}{ Female Reported HBV status of mothers } & $1,741(60.1) 362$ \\
\hline \multirow[t]{2}{*}{ Place of birth: } & Italy & 2,868 (98.9) \\
\hline & Elsewhere & $31(1.1)$ \\
\hline
\end{tabular}

Continuous variables are given as mean $\pm \mathrm{SD}$; categorical variables are given as $\mathrm{n}^{\circ}(\%)$

reduced periodicity of six months, and was temporarily prohibited from carrying out any highly invasive surgery.

The 2,899 vaccinated subjects were all HBsAg/anti-HBc negative. One thousand seven hundred and forty one students (60.1\%) were female and 2,868 (98.9\%) were of a Caucasian Italian ethnic background; 994 had received a course of 3 paediatric doses $(10 \mu \mathrm{g})$ of recombinant hepatitis $B$ vaccine at their 3rd, 5th and 11th month of postnatal life, and 1,905 had received a course of 3 adult doses $(20 \mu \mathrm{g})$ of the same vaccine when 12 years old. The majority $(84.2 \%)$ of the students had an anti-HBs titre $>10$ IU/L. Only 362 students were sure that their mothers were HBV negative at the time of giving birth to them (Table 1).

Compared with students vaccinated at age 12 years, those vaccinated in infancy were younger $(21.5 \pm 1.0$ vs. $28.0 \pm 4.5, p<0.000$ ), more frequently female (72\% vs. $54 \%, p<0.000$ ) (Table 2) and had a significantly lower prevalence of individuals with a low $(<10 \mathrm{IU} / \mathrm{L})$ antiHBs titre (12.3 vs. $22.6 \%$ ) (Table 2).

The subjects with an anti-HBs titre $<10$ IU/L were younger, more frequently attending a healthcare profession school, and had more frequently been vaccinated in infancy (Table 3 and Fig. 1). The 32 unvaccinated HBsAg/anti$\mathrm{HBs} / \mathrm{anti}-\mathrm{HBc}$ negative subjects were required to undergo the complete HBV prophylaxis programme.

\section{Discussion}

In 2013, the Integrated Epidemiological System for Acute Viral Hepatitis (SEIEVA) reported an incidence of HBV infections in Italy of only 1 per 100,000 individuals; about $20 \%$ of acute HBV infections concerned immigrants, especially from Eastern Europe and Africa, areas highly endemic for HBV [14]. This large reduction in the incidence of $\mathrm{HBV}$ infection is certainly also linked to the vaccination programme for infants and 12-year-old adolescents in Italy since 1991.

No student that had been vaccinated was found to have been infected with $\mathrm{HBV}$, as reflected by the absence of positivity to serum HBsAg or anti-HBc after a mean period of nearly 18 years. Thus, the efficacy of the programme is excellent (i.e., $100 \%$ ). However, we found that factors such as older age decreased immunogenicity, and that low levels of anti-HBs could be predictive of non-protection. Other factors, such as smoking and obesity, not assessed in our study, may also be involved in decreased immunogenicity [15-17].

Several studies have reported that $85-90 \%$ of those vaccinated as adolescents have anti-HBs levels $>10 \mathrm{mIU} / \mathrm{mL}$ when measured 10 years after vaccination. This percentage was $40-60 \%$ for those vaccinated as infants, as measured 15-20 years after vaccination $[18,19]$. The possible causes of the low anti-HBs titres in adult subjects vaccinated in infancy could be a lower interaction between $\mathrm{B}$ and $\mathrm{T}$ cells in babies, and in some cases, the presence of serum anti-HBs in mothers might affect the response to the HBV vaccine in babies $[20,21]$. This is coherent with our finding that $87.7 \%$ of students vaccinated during adolescence had an anti-HBs titre $>10 \mathrm{IU} / \mathrm{L}$, while only $77.4 \%$ of those vaccinated in infancy had a titre $>10 \mathrm{IU} / \mathrm{L}$. Closer analysis of our results revealed that healthcare profession students, who were mainly female, had a higher percentage of individuals with

Table 2 Characteristics of the 2,899 vaccinated students stratified by age at vaccination

\begin{tabular}{|c|c|c|c|c|}
\hline & & Vaccinated in infancy & Vaccinated at age 12 years & $p$ \\
\hline \multicolumn{2}{|l|}{ No. of students } & 994 & 1,905 & \\
\hline \multicolumn{2}{|l|}{ Age in years } & $21.8 \pm 1.0$ & $28.0 \pm 4.5$ & 0.000 \\
\hline \multicolumn{2}{|l|}{ Females } & $715(72)$ & $1,026(54)$ & 0.000 \\
\hline \multirow[t]{2}{*}{ Place of birth: } & Italy & $987(99.3)$ & $1,881(98.7)$ & \multirow[t]{2}{*}{ n.s. } \\
\hline & Elsewhere & $7(0.7)$ & $24(1.3)$ & \\
\hline \multirow[t]{3}{*}{ Attending: } & School of medicine & $56(5.6)$ & $839(44)$ & \multirow[t]{3}{*}{$0.000^{*}$} \\
\hline & Healthcare profession school & 938 (94.4) & $468(24.6)$ & \\
\hline & Postgraduate medical school & 0 & $598(31.4)$ & \\
\hline \multicolumn{2}{|c|}{ Years since vaccination } & $22.1 \pm 1.1$ & $16.1 \pm 3.1$ & 0.000 \\
\hline \multicolumn{2}{|c|}{ Students with $\mathrm{HBsAb}<10 \mathrm{IU} / \mathrm{L}$} & $224(22.6)$ & $235(12.3)$ & 0.000 \\
\hline \multicolumn{2}{|c|}{ Students with HBsAb >10 IU/L } & $770(77.4)$ & $1670(87.7)$ & 0.000 \\
\hline
\end{tabular}

*Healthcare professions school students vs. all medical school students (graduate + postgraduate)

Continuous variables are given as mean $\pm \mathrm{SD}$; categorical variables are given as $\mathrm{n}^{\circ}(\%)$ 
Table 3 Characteristics of students stratified by anti-HBs titre

\begin{tabular}{|c|c|c|c|c|}
\hline & & $<10 \mathrm{IU} / \mathrm{L}$ & $>10 \mathrm{IU} / \mathrm{L}$ & $P$ \\
\hline No. of students & & $459(15.8)$ & $2,440(84.2)$ & \\
\hline Age in years & & $24 \pm 5.3$ & $26 \pm 5.1$ & 0.000 \\
\hline Females & & $269(58.6)$ & $1,472(60.3)$ & n.s \\
\hline \multirow[t]{3}{*}{ Attending: } & School of medicine & $112(24.4)$ & $792(32,5)$ & $0.0001^{*}$ \\
\hline & Healthcare professions school & $254(55.3)$ & $1,175(48.1)$ & \\
\hline & Postgraduate medical school & $93(20.3)$ & $473(19.4)$ & \\
\hline \multirow[t]{2}{*}{ Vaccinated } & in infancy & $235(51.2)$ & $759(31.1)$ & 0.000 \\
\hline & at age 12 years & $224(48.8)$ & $1,681(68.9)$ & \\
\hline
\end{tabular}

*Healthcare profession school students vs. all medical school students (graduate + postgraduate). Continuous variables are given as mean \pm SD; categorical variables are given as $\mathrm{n}^{\circ}(\%)$

an anti-HBs titre $<10 \mathrm{IU} / \mathrm{L}$. Indeed, this group was the youngest (they were assessed during their first year of studies, rather than during the third year, as done for the medical students, as required by the risk assessment document) and therefore had the highest number of subjects who had received compulsory vaccination in infancy.

HCP and healthcare students are reported to have the highest occupational risk for $\mathrm{HBV}$ infection, with approximately 66,000 HBV infections per year worldwide. Therefore, testing medical students for anti-HBs levels may be warranted as they represent a high-risk population [22-24]. This is particularly relevant in countries where HBV vaccination programmes for infants and adolescents has been introduced but no post-vaccination serological testing is done, making it impossible to identify unvaccinated subjects $[25,26]$. In our group, 33 students had not been vaccinated, one of whom had acquired an HBV infection. Italian law (Article 279 of Legislative Decree n. 8, 19 April 2008) requires only to review the vaccination status of HCP and healthcare students prior to employment or to enrolment in a course with a documented possible risk of HBV contagion. However, the decree currently only recommends that unvaccinated individuals be vaccinated; in other words, there is no clear legal obligation to do so. The vaccination procedure is charged to the employer, and the occupational physician must perform the vaccination procedure [27], but even if the non-vaccination of an unvaccinated worker does not lead to automatic discharge, it may lead the occupational physician to limit activities deemed risky.

In our case, all 33 unvaccinated subjects were sent for vaccination and re-evaluation of anti-HBs titre. The HBsAg positive subject was put on antiviral therapy and was included in a follow-up programme monitoring viral load.

In HCP and healthcare students, it is necessary to assess anti-HBs titre either at matriculation or at the start of employment in order to identify subjects with levels $<10 \mathrm{IU} / \mathrm{L}$. In fact, although the current WHO view is that subjects with an anti-HBs titre $<10 \mathrm{IU} / \mathrm{L}$ still retain memory immunity, and no booster dose is

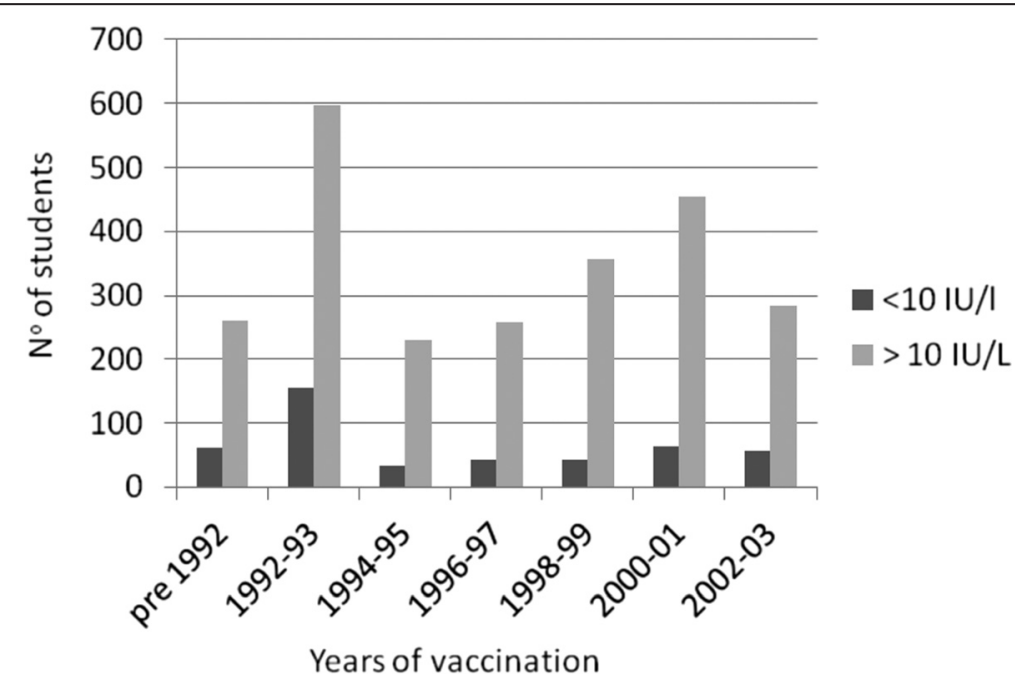

Fig. 1 Number of vaccinated students with an anti-HBs titre $<10 \mathrm{IU} / \mathrm{L}$ or $>10 \mathrm{IU} / \mathrm{L}$, stratified by year of vaccination 
necessary as part of a routine immunization programme [27], a more protective approach should be adopted for healthcare workers under continuous risk of exposure to HBV [28, 29]. To distinguish between non-responsive subjects and those whose titres have waned over time but who are still protected, a 'challenge' or 'booster' dose should be administered and titres rechecked 1-2 months later. Those presenting with titres $\geq 10 \mathrm{IU} / \mathrm{L}$ can be considered protected and not needing additional testing or vaccination, whereas those presenting with titres that are still $<10 \mathrm{IU} / \mathrm{L}$ after the challenge dose should be referred to a vaccination programme. Indeed, previous studies of young subjects who had been vaccinated in infancy have indicated that a single-dose booster may not reliably induce an anti-HBs response, suggesting that humoral memory immunity reduces with time. Lu CY et al. showed that the HBsAg-specific T cell immune response was negative in $27.2 \%$ of subjects who had received a booster 15 to 18 years after HBV vaccination in infancy [30]; a more recent study of young adults (ages ranging from 18.6 to 20.5 years) who had been immunized against HBV as infants reported that nearly $20 \%$ of subjects with $\mathrm{HBsAb}<10 \mathrm{IU} / \mathrm{L}$ failed to respond to a booster injection [31].

\section{Conclusion}

The present study evaluates the efficacy and immunogenicity of HBV vaccination in a large series of subjects with a high risk of being exposed to HBV. The results of this study suggest that assessment of HBV markers is worthwhile to identify the small number of medical students and HCP that may not have been vaccinated, such as immigrants from countries without universal immunisation, and HBV carriers that exist for various reasons, including rare failure in protection or uptake after immunisation.

\section{Abbreviations \\ HBV: hepatitis B virus; WHO: World Health Organisation; HBsAg: HBV surface antigen; HCP: healthcare personnel.}

\section{Competing interests}

All the authors of the manuscript declare that they have no conflict of interest in connection with this paper.

\section{Authors' contributions \\ $\mathrm{ML}, \mathrm{AC}, \mathrm{NS}, \mathrm{SDP}$ and NC designed the study, performed data analysis and made valuable contributions to the manuscript. AN, CW, EMG, AA and EDF were involved in data analysis and made valuable contributions to the manuscript, ADR, GDG and APRS made valuable contributions to the manuscript revision. All authors read and approved the final manuscript.}

\section{Acknowledgements}

We thank Alessandro Izzo, Second University of Naples, for his support and for his assistance in data collection.

\section{Author details}

${ }^{1}$ Department of Experimental Medicine, Section of Hygiene, Occupational Medicine and Forensic Medicine, Second University of Naples, Via dei Crecchi 16, Naples 80133, Italy. ${ }^{2}$ Department of Orthodontics, Second University of Naples, Naples, Italy. ${ }^{3}$ Department of Mental Health and Public Medicine, Section of Infectious Diseases, Second University of Naples, Naples, Italy.
${ }^{4}$ Institute for Health Services, Research in Dermatology and Nursing, University Medical Centre Hamburg-Eppendorf, Hamburg, Germany. ${ }^{5}$ Institution for Statutory Accident Insurance and Prevention in Healthcare and Welfare Services, Hamburg, Germany. ${ }^{6}$ Department of Operative Dentistry, Dental School, UFMG - Universidade Federal de Minas Gerais, Belo Horizonte, MG, Brazil.

Received: 3 March 2015 Accepted: 26 October 2015

Published online: 04 November 2015

\section{References}

1. Kane MA. Global status of hepatitis B immunization. Lancet. 1996;348:696.

2. Lee WM. Hepatitis B virus infection. N Engl J Med. 1997;337:1733-45.

3. Dannetun E, Tegnell A, Torner A, Giesecke J. Coverage of hepatitis B vaccination in Swedish healthcare workers. J Hosp Infect. 2006;63(2):201-4.

4. De Schryver A, Claesen B, Meheus A, van Sprundel M, François G. European survey of hepatitis B vaccination policies for healthcare workers. Eur J Public Health. 2011;21(3):338-43. doi:10.1093/eurpub/ckq122.

5. Bhattarai S, K C S, Pradhan PM, Lama S, Rijal S. Hepatitis B vaccination status and Needle-stick and Sharps-related Injuries among medical school students in Nepal: a cross-sectional study. BMC Res Notes. 2014;7:774. doi:10.1186/1756-0500-7-774.

6. Lamberti M, Muoio M, Monaco MG, Uccello R, Sannolo N, Mazzarella G, et al. Prevalence of latent tuberculosis infection and associated risk factors among 3,374 healthcare students in Italy. J Occup Med Toxicol. 2014;9(1):34. doi:10.1186/s12995-014-0034-5.

7. Gasparini R, Pozzi T, Montomoli E, Fragapane E, Civai R, Mara E. Vaccination against hepatitis $B$ : length of protection among populations at risk. Prev Med Hyg. 1998;39:37-41.

8. Trevisan A, Bruno A, Mongillo M, Morandin M, Pantaleoni A, BorellaVenturini $M$, et al. Prevalence of markers for hepatitis $B$ virus and vaccination compliance among medical school students in Italy. Infect Control Hosp Epidemiol. 2008:29(12):1189-91. doi:10.1086/592414.

9. Zanetti AR, Mariano A, Romanò L, D'amelio R, Chironna M, Coppola RC, et al. Long-term immunogenicity of hepatitis $B$ vaccination and policy for booster: an Italian multicentre study. Lancet. 2005;366:1379-84.

10. Lamberti M, Uccello R, Monaco MG, Muoio M, Sannolo N, et al. Prevalence of latent tuberculosis infection and associated risk factors among 1557 nursing students in a context of low endemicity. Open Nurs J. 2015;9:10-4. doi:10.2174/1874434601509010010.

11. Uccello R, Monaco MG, Feola D, Garzillo EM, Muoio M, Sannolo N, et al. Managment of tuberculosis in an University of Campania. G Ital Med Lav Ergon. 2012:34:299-301.

12. Italian Medicines Agency: Linee guida per la classificazione e conduzione degli studi osservazionali sui farmaci. Gazzetta Ufficiale 2008, 76. 31/03/ 2008. http://www.agenziafarmaco.gov.it/allegati/det_20marzo2008.pdf.

13. Italian Law decree n. 196, 30 June 2003 (article 24): http://www.camera.it/ parlam/leggi/deleghe/03196dl.htm.

14. Sistema Epidemiologico Integrato dell'Epatite Virale Acuta : Tassi annuali /100.00 per età, sesso ed area geografica delle epatiti Virali Acute. SEIEVA 2013. http://www.iss.it/binary/seie2/cont/SEIEVA_Tassi_2013.pdf.

15. Wood RC, MacDonald KL, White KE, Hedberq CW, Hanson M, Osterholm MT. Risk factors for lack of detectable antibody following hepatitis B vaccination of Minnesota health care workers. JAMA. 1993;270:2935-9.

16. Yu AS, Cheung RC, Keeffe EB. Hepatitis B vaccines. Infect Dis Clin North Am. 2006;20(1):27-45.

17. Rosenberg C, Bovin NV, Bram LV, Flyvbjerg E, Erlandsen M, Vorup-Jensen T, et al. Age is an important determinant in humoral and $T$ cell responses to immunization with hepatitis B surface antigen. Hum Vaccin Immunother. 2013;9(7):1466-76. doi:10.4161/hv.24480

18. Chiara F, Bartolucci GB, Mongillo M, Ferretto L, Nicolli A, Trevisan A. Hepatitis $B$ vaccination at three months of age: a successful strategy? Vaccine. 2013;31(13):1696-700. doi:10.1016/j.vaccine.2013.01.046.

19. Stroffolini T, Guadagnino V, Caroleo B, De Sarro G, Focà A, Liberto MC, et al. Long-term immunogenicity of hepatitis $B$ vaccination in children and adolescents in a southern Italian town. Infection. 2012;40(3):299-302. doi:10.1007/s15010-011-0233-2.

20. Zhu CL, Liu P, Chen T, Ni Z, Lu LL, Huang F, et al. Presence of immune memory and immunity to hepatitis $B$ virus in adults after neonatal hepatitis B vaccination. Vaccine. 2011;29(44):7835-41. doi:10.1016/ j.vaccine.2011.07.098 
21. Lo KJ, Lee SD, Tsai YT, Wu TC, Chan CY, Chen GH, et al. Long-term immunogenicity and efficacy of hepatitis $B$ vaccine in infants born to HBeAg-positive HBsAg-carrier mothers. Hepatology. 1988;8(6):1647-50.

22. Caciari T, Casale T, Tomei G, Capozzella A, Trovè L, Lepanto R, et al. Biological risk among health workers. G Ital Med Lav Ergon. 2013;35(3):163-7.

23. Narin I, Gedik H, Voss A. Blood and body fluid exposures in health-care settings: risk reduction practices and postexposure prophylaxis for health-care workers. Curr Infect Dis Rep. 2012;14(6):607-11. doi:10.1007/s11908-012-0297-x.

24. Bhat $M$, Ghali $P$, Deschenes $M$, Wong P. Hepatitis B and the infected health care worker: public safety at what cost? Can J Gastroenterol. 2012;26(5):257-60.

25. De Schryver A, Claesen B, Meheus A, Hambach R, van Sprundel M, François $\mathrm{G}$. Hepatitis B vaccination policies for student healthcare workers in Europe. J Hosp Infect. 2014;86(2):147-50. doi:10.1016/j.jhin.2013.11.005.

26. De Schryver A, Claesen B, Meheus A, Hambach R, van Sprundel M, François G. Hepatitis B vaccination policies for student healthcare workers in Europe. J Hosp Infect. 2014;86(2):147-50. doi:10.1016/j.jhin.2013.11.005.

27. Publication WHO. Hepatitis B vaccines: WHO position paper-recommendations. Vaccine. 2010;28:589-90

28. Hong Kong Department of Health. Hepatitis B. In: Salisbury D, Ramsay M, Noakes K, Salisbury D, Ramsay M, Noakes K, editors. Immunisation against infectious disease "The Green Book". London: Department of Health; 1996. p. 161

29. Coppola N, Corvino AR, De Pascalis S, Signoriello G, Di Fiore E, Nienhaus A, et al. The long-term immunogenicity of recombinant hepatitis B virus (HBV) vaccine: contribution of universal HBV vaccination in Italy. BMC Infect Dis. 2015:25:15-149. doi:10.1186/s12879-015-0874-3.

30. Lu CY, Ni YH, Chiang BL, Chen PJ, Chang MH, Chang LY, et al. Humoral and cellular immune responses to a hepatitis B vaccine booster 15-18 years after neonatal immunization. J Infect Dis. 2008;197(10):1419-26.

31. Saffar H, Saffar MJ, Ajami A, Khalilian AR, Shams-Esfandabad K, Mirabi AM Long-term T-cell-mediated immunologic memory to hepatitis B vaccine in young adults following neonatal vaccination. Hepat Mon. 2014;14(9):e22223. doi:10.5812/hepatmon.22223.

\section{Submit your next manuscript to BioMed Central and take full advantage of:}

- Convenient online submission

- Thorough peer review

- No space constraints or color figure charges

- Immediate publication on acceptance

- Inclusion in PubMed, CAS, Scopus and Google Scholar

- Research which is freely available for redistribution

Submit your manuscript at www.biomedcentral.com/submit 